\title{
Integración de captación activa y pasiva en viviendas unifamiliares de emprendimientos inmobiliarios
}

\author{
Active and passive solar energy integration in single- \\ family dwelling roofs of real estate developments
}

\section{Esteban Felipe Zalamea-León Rodrigo Hernán García-Alvarado}

\section{Resumen \\ A} partir de modelos inmobiliarios vigentes, se analiza la posibilidad de construir viviendas que abastezcan demandas energéticas propias y provean energía excedente (Plus-Energy House),. Para ello se revisa un catastro de tipologías y estadísticas de consumos, seleccionando un caso representativo en el que se proponen alteraciones de diseño pasivo y se ejecutan simulaciones energéticas integrando tecnologías activas en las que se determina una producción factible frente a las demandas. Se despliegan tecnologías solares en integración arquitectónica BIPV, BISTw, BIPVTa y BIPVTw individualmente o combinadas buscando maximizar la capacidad de producción para autoconsumo, comparándose temporalmente con demandas características para identificar déficits y excedentes característicos promedios de días representativos de verano, invierno y de épocas interestacionales. Por último se obtiene el balance anual, el cual refleja un abastecimiento de aproximadamente el $174 \%$ al desplegarse solamente tecnología BIPV y $251 \%$ al integrar tecnologías híbridas térmicas fotovoltaicas con fluido líquido y fluido aire (BIPVTw) (BIPVTa).

Palablas claves: Vivienda. Eficiencia energética. Energía solar. Edificación Energéticamente Positiva.

Esteban Felipe Zalamea-León Universidad de Cuenca

Cuenca -Ecuador

Rodrigo Hernán García-

Alvarado

Universidad del Bio Bio Concepción - Chile

Recebido em 19/05/16

Aceito em 24/11/16

\section{Abstract}

This study analyses the possibility of achieving negative energy demands in singlefamily housing (Plus-Energy House). Through the integration of energy efficiency measures jointly with active solar systems, it is possible to obtain high performance energy models. In order to demonstrate this, we performed energy simulations integrating active solar systems, and also possible self-shading and separations between dwellings. We analysed the deployment of BIPV, BISTw, BIPVTa and BIPVTw technologies individually and in different combinations between them with the purpose of maximizing production capability for selfconsumption, comparing them with residential demands in order to identify energy deficits and surpluses in different seasons. The measurements were taken hourly on typical days in summer, winter and intermediary seasons. Finally, an annual balance was obtained, showing energy surpluses of approximately $174 \%$ when deploying only BIPV collectors and $251 \%$ when combining BIPVTw and BIPVTa.

Keywords: Architecture. Housing. Energy efficiency. Solar energy. Plus-Energy Buildings. 


\section{Introducción}

El abastecimiento energético a partir de tecnologías de captación de energía solar activa se incrementa significativamente al reducirse las demandas residenciales con la adopción de estrategias pasivas, en tal magnitud que es posible alcanzar edificaciones con balance de demandas energéticas neutras e incluso negativas (ATHIENITIS et al., 2011; HASTINGS; WALL, 2007; NOGUCHI, 2008).

El contexto de este estudio es la ciudad de Concepción, que posee clima estacional no extremo y que está próxima a la costa del Pacífico, a $36,5^{\circ}$ de latitud sur. Concepción es la comuna central de la principal área metropolitana del sur de Chile, con una población estimada de 230.729 habitantes (INE, 2015). La temperatura anual promedio es de $12,4{ }^{\circ} \mathrm{C}$, lo que condiciona una alta demanda térmica. Al comparar estas condiciones frente a las de ciudades del sur de Europa que están emplazadas a similar distancia de la línea ecuatorial, pero hacia el hemisferio norte - por ejemplo, en Sevilla (lat. $38^{\circ} \mathrm{N}$ ) o Barcelona (lat. $\left.41^{\circ} \mathrm{N}\right)$ - puede constatarse que estas últimas poseen temperaturas promedio superiores $\left(19,2{ }^{\circ} \mathrm{C}\right.$ y $16,1{ }^{\circ} \mathrm{C}$, respectivamente) (AEMET, 2015), frente a una incidencia y a una altura solar parecidas. Estos factores particulares de locación y clima resultan en demandas energéticas particulares con distintos requerimientos. Por otra parte, estas diferencias limitan la transferencia directa de conocimiento de investigaciones de diferentes contextos, a pesar de que exista una coincidencia en lo que se refiere a la latitud en los dos hemisferios y a la similitud en cuanto a altura solar frente a la envolvente de las edificaciones. Particularmente en el contexto de este estudio, existe un déficit en la calidad de construcción, lo cual implica demandas térmicas considerables que deben tenerse en cuenta paralelamente (CELIS et al., 2012; FISSORE, 2009; WEGERTSEDER et al., 2014).

En este escenario, lograr viviendas Net-Zero o neutrales en el balance anual, contrarrestando las demandas típicas habituales, implica la instalación de considerables superficies colectoras de más de 0,6 $\mathrm{m}^{2}$ por $\mathrm{m}^{2}$ construido (ZALAMEA; GARCÍA; SÁNCHEZ, 2016). No obstante, se ha demostrado que las demandas energéticas típicas son mitigables en gran medida a través de estrategias pasivas (CELIS et al., 2012; HATT et al., 2012). Luego, es natural suponer que, al desplegar una captación solar en su máxima magnitud, es factible obtener excedentes después de suplir las demandas propias y que estos pueden aprovecharse para otros usos adicionales, además de los netamente residenciales. Esta condición está presente en las denominadas viviendas Plus Energy (DISCH, 2010). Con ello es posible contribuir con la red urbana para lograr zonas energéticamente eficientes (SALPAKARI; MIKKOLA; LUND, 2016).

En un estudio previo se ha analizado la capacidad global del conjunto de viviendas de la tipología; el crecimiento en conjuntos de casas entre 2006 y 2013 es de 3.133 unidades aproximadamente, correspondiente al 90,6 \% de los permisos emitidos (ZALAMEA; GARCÍA ALVARADO, 2014). También se han revisado casos extremos de acuerdo con el potencial solar por geometría con superior e inferior capacidad para integrar captadores, denotando condiciones de diseño que impliquen aptitud para obtener una recolección solar activa relevante (ZALAMEA; GARCÍA; SÁNCHEZ, 2016). Pero el modelo con potencial superior solamente por geometría de cubierta muestra un faldón con importante capacidad en uno de los costados, que si bien implica una irradiación importante en recolección neta -tanto la fachada frontal como la posterior en donde están los vanos captadores pasivos- no muestra una accesibilidad solar adecuada. Es necesario, entonces, encontrar una alternativa que viabilice una incidencia solar relevante, tanto en techumbre como en vanos simultáneamente, al igual que considerar medidas de acondicionamiento ambiental pasivo y utilización de equipamiento energéticamente eficiente.

Las tecnologías solares activas a analizarse son: Tecnología Fotovoltaica Integrada a Edificación (BIPV) (JELLE, 2016), Tecnología Solar Térmica con Fluido Líquido Integrada a Edificación (BISTw) (KALOGIROU, 2015); además de tecnologías híbridas térmicas-fotovoltaicas, con fluido aire (BIPVTa) (ATHIENITIS et al., 2011) y fluido líquido (BIPVTw) (TRIPANAGNOSTOPOULOS et al., 2002; ZONDAG, 2008). Se trata de opciones probadas con características diversas para enfrentar demandas residenciales y que consideramos como alternativas para la ciudad de Concepción como consecuencia de demandas e irradiación disponible. Para estimar la eficiencia y rendimiento térmico de los colectores planteados, se utiliza la herramienta F-Chart programada a partir de un modelo matemático referente desarrollado por la Universidad de Concepción. Tal herramienta ha sido contrastada con una segunda F-Chart publicada por el Ministerio de Energía de Chile (PROGRAMA...; MINENERGIA, 2017). Estas herramientas se 
programan a partir de ecuaciones que permiten prever el rendimiento de los colectores térmicos con un margen de error de entre $1,1 \%$ y $4,7 \%$ frente a métodos de simulación dinámica complejos, y hasta un $15 \%$ frente a datos de mediciones reales (HABERL; CHO, 2014). Para estimar la recolección solamente térmica en fluido líquido, se adoptan las especificaciones y eficiencia del modelo Wunder CLS 1808 de Solimpeks@ ${ }^{@}$. Los parámetros de eficiencia térmica del mencionado producto son: coeficiente de absorción $\eta_{0}=0,763$ y coeficiente de pérdida térmica $a_{0}=3,514 \mathrm{Wm}^{-2} \mathrm{~K}^{-1}$ en una superficie recolectora de $1,23 \mathrm{~m}^{2}$. Las tecnologías descritas, así como su rendimiento, han sido analizadas y aplicadas previamente en el contexto (CAMPOS, 2015; ZALAMEA; GARCÍA ALVARADO, 2014; ZALAMEA LEÓN; GARCÍA ALVARADO; SÁNCHEZ ARRIAGADA, 2016). Los formatos y eficiencias de los colectores son los mismos utilizados en un estudio previo (ZALAMEA LEÓN; GARCÍA ALVARADO; SÁNCHEZ ARRIAGADA, 2016). Es decir: para placas PV el módulo dimensional es $1660 \mathrm{~mm}$ x 830 mm x 45 $\mathrm{mm}$; la eficiencia eléctrica $\mathrm{PV}$ es de $12 \%$ respecto a la irradiación disponible (considerando una eficiencia promedio de $16 \%$ y pérdidas esperadas de un 25 \%) (PELLAND; POISSANT, 2006). Para la recolección híbrida BIPVa, la producción térmica considerada es de tres veces la producción eléctrica por eficiencia directa, según lo estimado en estudios de referencia (HACHEM, 2012; SOLARWALL, 2015); para la eficiencia eléctrica con colector híbrido se considera un $8 \%$ (CAMPOS, 2015) y el formato para colectores BISTw y BIPVTw es $1660 \mathrm{~mm}$ x $830 \mathrm{~mm}$ x 90 mm. Los excedentes se expresan en KWh al año, comparándose con la posible capacidad de alimentación de un automóvil eléctrico con un rendimiento de $6 \mathrm{~km}$ por $\mathrm{kWh}$, la cual es una magnitud factible (CONSEJERÍA DE HACIENDA DE MADRID, 2012).

Frente a la rentabilidad y al tiempo de retorno de inversión, existe una variabilidad y una dependencia fuerte en cuanto a la oscilación de precios energéticos y con respecto a cada una de las tecnologías. Campos (2015) ha encontrado que, para la ciudad de Concepción, la recolección solar térmica el período de retorno es de cinco años y tiene perspectiva de constante mejora para el futuro. Para el fotovoltaico, no obstante, se espera que la instalación se pague en 15 años, por lo cual actualmente no es una inversión rentable. Sin embargo, existe una proyección de incremento de costos de la electricidad y la reducción constante del precio de las celdas fotovoltaicas; en los Estados Unidos, por ejemplo, se reporta que entre
2007 y 2013 ha existido un abaratamiento del KWh en PV a la mitad, y desde 1998 hubo una reducción promedio de $6 \%$ a un $8 \%$ por año en el precio(FELDMAN et al., 2014). La tendencia futura muestra escenarios favorables siendo rentables en los próximos cinco años. Para los colectores híbridos es más complejo establecer un retorno de inversión por tratarse de una tecnología reciente y por la ausencia de oferta de la misma en el medio. No obstante, en el ámbito extranjero este tipo de tecnología todavía es poco competitiva por el alto precio y el escaso desarrollo comercial. A pesar de ello se presenta como una alternativa interesante al optimizar espacio con respecto a instalar colectores fotovoltaicos y térmicos por separado, simplificando la instalación; adicionalmente, la superior exergía de los colectores híbridos muestran que se trata de una opción cada vez más rentable (CHEN; YIN, 2016). También es esencial un impulso político y un subsidio en etapa inicial para la masificación de estas tecnologías; por ahora, el Gobierno Chileno ha impulsado leyes para promover la integración solar térmica y fotovoltaica (MINENERGIA, 2009)(MINENERGIA, 2013) a través del subsidio en el caso térmico y de la posibilidad de conexión a red en caso de fotovoltaico. Sin embargo, se requiere una verdadera masificación para que sea posible una reducción efectiva de los costos de instalación y mantenimiento.

\section{Propuesta y estimación de integración de captación solar pasiva y activa conjuntamente en vivienda de elevado potencial}

Es poco lo que se puede contrarrestar con captación solar activa per se si las demandas no son controladas. En el clima de Concepción, de estaciones marcadas no extremas, el lograr una vivienda Net-Zero integrando recolección solar activa es poco factible de no reducirse las demandas promedio. En climas más rigurosos con desbalances estacionales más pronunciados, se ha demostrado que es factible lograr casas energéticamente neutras (CHARRON; ATHIENITIS, 2006) e incluso con producción que excede las demandas (KAZANCI et al., 2014), lo cual posibilita que edificaciones contribuyan a suplir demandas externas, como un aporte para lograr Comunidades Net-Zero (CARLISLE; GEET; PLESS, 2009; LUND, 2012)

Este trabajo es complementario a otros preliminares, en los que se realizaron levantamientos de viviendas en conjuntos 
residenciales de emprendimientos inmobiliarios (ZALAMEA; GARCÍA ALVARADO, 2014), estimaciones estadísticas de demandas (GARCÍA et al., 2014) y análisis estadístico de geometría de techumbre en modelos con considerable capacidad y déficit de aptitud geométrica (ZALAMEA LEÓN; GARCÍA ALVARADO; SÁNCHEZ ARRIAGADA, 2016). A partir de los mencionados estudios es factible detectar aquellos modelos que posibilitan, no solamente una elevada captación de irradiación en su techumbre, sino casos en los que se puede captar tanto irradiación pasiva como activa.

\section{Selección de caso}

Se identifica un modelo que muestra relevantes posibilidades tanto para la captación activa como pasiva conjunta (Figura 1) que se denominará en adelante Modelo $C$. Al observar todos los casos se concluye que, efectivamente, existen casos con atributos importantes. No obstante, la opción seleccionada posee en su costado posterior faldones diáfanos con alta potencialidad de captación solar por superficie disponible, inclinación y regularidad formal, complementarios a tres ventanales que sirven a dos habitaciones y al living-comedor, que proporcionan adicionalmente una relevante recolección pasiva. Adicionalmente, en el costado opuesto al potencial soleamiento (fachada frontal) están el acceso, escaleras, dos baños y solamente una habitación impedida de irradiación directa. De esta manera, se infiere que se trata de una alternativa que, con una orientación adecuada, posibilita lograr una importante incidencia solar tanto en el techumbre como en la fachada. Se ha considerado importante el reinterpretar un modelo desde las tipologías existentes para que el caso sea representativo, más que crear un prototipo desde cero.

En el mismo loteo en el que se emplaza el Modelo $C$, existen otros que son el resultado de variaciones leves respecto al seleccionado. Estas alternativas, además de poseer un relevante potencial solar, tienen condiciones de agrupamiento en forma aislada y pareada. Incluso se observa (aunque no está proyectado actualmente) que poseen potencial para disponerse en agrupación continua, porque los vanos están desplegados sobre todo en las fachadas delantera y posterior, haciendo prescindibles las brechas existentes en los costados (Figura 2).

Figura 1 - Selección de Modelo C

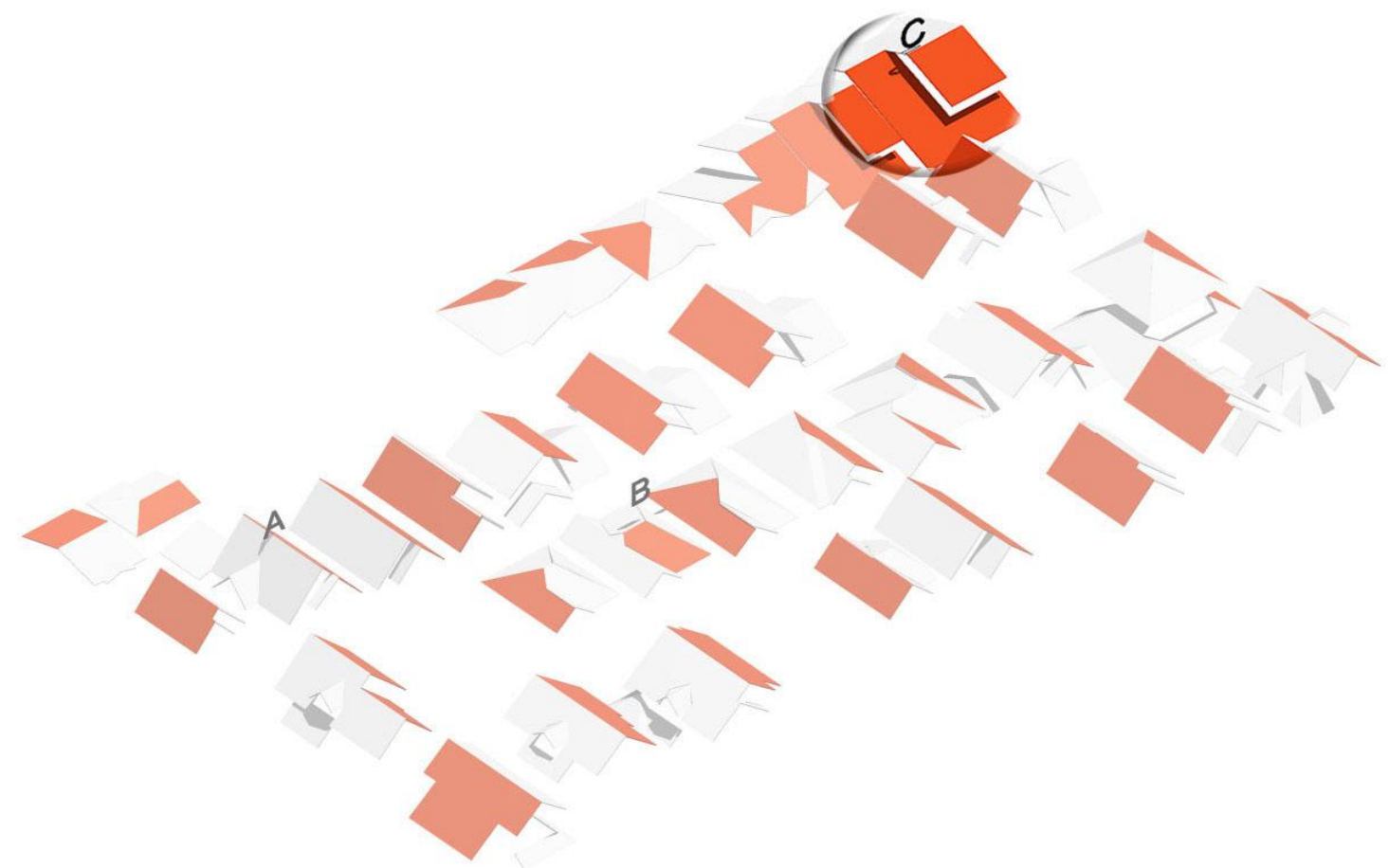

448 Zalamea-León, E. F. ; García-Alvarado, R. H. 
Figura 2 - Modelo C en su configuración original en plantas y en 3D

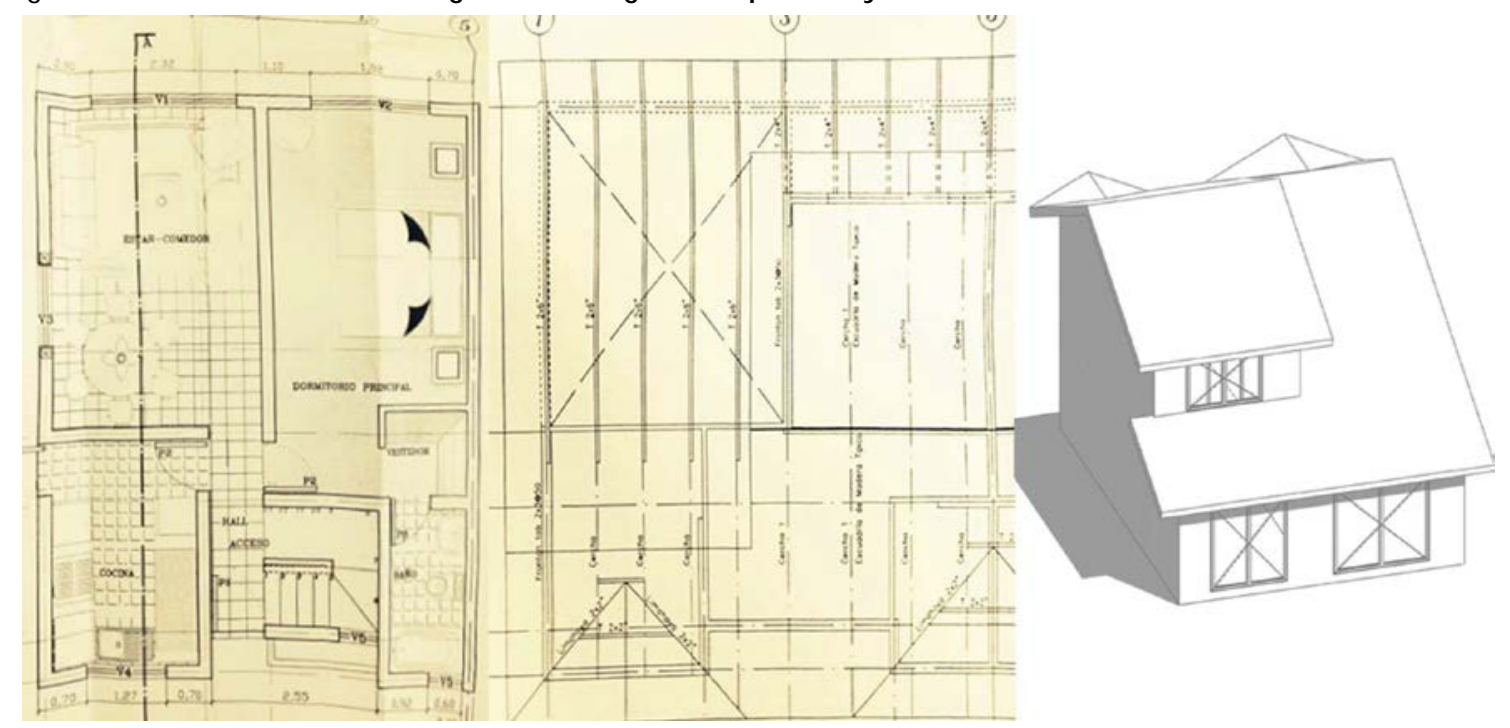

No obstante, se observa la necesidad de editar la volumetría general y la forma de techumbre concretamente, ya que, si bien existen dos segmentos de alas orientados coincidentemente y que sumados poseen una relevante superficie captadora, estos no están dispuestos en un solo nivel, lo que conlleva a segmentos intersombreados entre faldones. Por esta razón se edita el modelo para lograr una configuración de techumbre para que, con cambios menores, se pueda lograr una vivienda con un importante potencial solar pasivo y activo conjunto. Al editar el modelo con la creación de una habitación adicional, se mantiene la dimensión de faldones y la posible incidencia de irradiación tanto en facetas potencialmente colectoras como también la incidencia pasiva al interior. Adicionalmente, al dimensionar los aleros se regula el ingreso solar en invierno y se bloquea durante el verano. La distribución longitudinal de los espacios y los vanos en fachadas frontal y posterior de las dos plantas contribuye a una adecuada ventilación cruzada. En consecuencia, se logra una vivienda de dos plantas con tres habitaciones, living $\mathrm{y}$ comedor, con abundante soleamiento en temporada fría. El modelo de vivienda resultante se presenta en la Figura 3. Se configura además un modelo que, a pesar de la relevante superficie colectora, posee una volumetría compacta, con baja relación de superficie envolvente frente a la superficie construida que incide en una reducción de demandas por factor forma (GARCÍA ÁLVARADO; GONZÁLEZ, 2014).

El indicador de superficie de faldones captadores en relación con la superficie construida resultante es de 0,81. Otros indicadores geométricos luego de la readecuación geométrica se señalan en la Tabla
1. Esta tabla compara el Modelo C con otros casos de la misma tipología estudiados previamente (Modelos A y B) y que son representativos del máximo y del mínimo potencial solar para captación activa, respectivamente (ZALAMEA LEÓN; GARCÍA ALVARADO; SÁNCHEZ ARRIAGADA, 2016).

\section{Integración de medidas de eficiencia energética y recolección solar pasiva}

Se procede a revisar la envolvente exterior típica para proponer una alternativa con condiciones energéticas mejoradas. Para ello se establece un aislamiento equilibrado en cada una de las superficies aislantes con el exterior. Se despliega el aislamiento con poliestireno expandido en cada uno de los muros exteriores; se disponen además carpinterías de ventanas con vidrio cámara, aislamiento con poliestireno de alta densidad bajo la placa del piso y lana de vidrio en el cielo del piso superior. En las Tablas 2 y 3 se señala la materialidad, el espesor y los parámetros de conductividad, así como Valores $U^{1}$ resultantes de las especificaciones de acuerdo con el criterio mencionado, determinados por los softwares Trnsys $^{\circledR}$ - con su módulo Trnbuild $^{\circledR}-\mathrm{y}$ Ecodesigner $^{\circledR}$.

${ }^{1}$ Transmitancia térmica que indica la capacidad de aislamiento de los materiales. 
Figura 3 - Modelo C en su configuración editada para lograr un máximo potencial solar: plantas y 3D

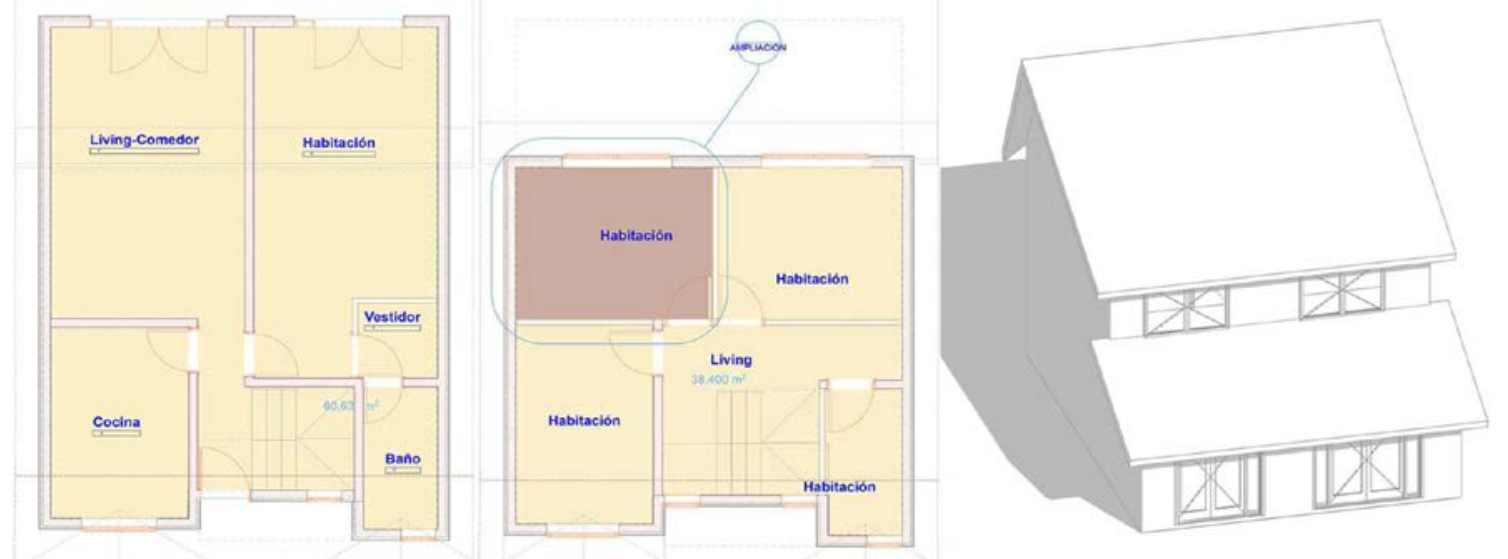

Tabla 1 - Producción versus demandas, márgenes de abastecimiento en energía y exergía de tres modelos: A y B - estudiados anteriormente (ZALAMEA LEÓN; GARCÍA ALVARADO; SÁNCHEZ ARRIAGADA, 2016) - y Modelo C

\begin{tabular}{|c|c|c|c|c|c|c|c|c|c|c|}
\hline \multicolumn{11}{|c|}{$\begin{array}{c}\text { Parámetros Comparativos Geométricos Viviendas de Casos Extremos acorde a indicador de superficie captadora frente } \\
\text { a construida (12) (19) y modelo editado para máximo potencial pasivo o activo }\end{array}$} \\
\hline$\frac{0}{\frac{0}{8}}$ & 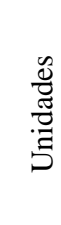 & 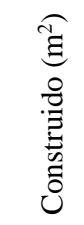 & 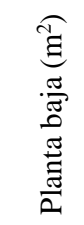 & 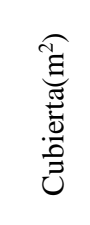 & 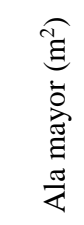 & 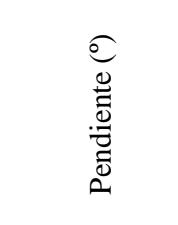 & 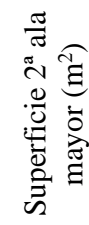 & 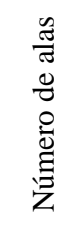 & 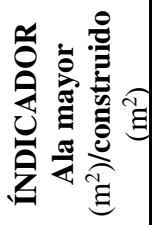 & 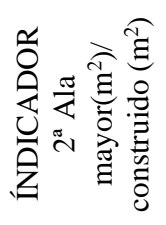 \\
\hline$A$ & 110 & 71,94 & 45,32 & 94,59 & 44,05 & $49,72^{\circ}$ & 36,86 & 5 & 0,6123 & 0,51 \\
\hline$B$ & 70 & 78,95 & 35,32 & 82,44 & 26,01 & SAMD $27,2^{\circ}$ & 15,2 & 6 & 0,329 & 0,19 \\
\hline$C$ & $50 *$ & 98,9 & 60,6 & 98,9 & 79,2 & AMD $24^{\circ}$ & 15,5 & $7 * *$ & 0,801 & 0,16 \\
\hline
\end{tabular}

Nota: *cantidad de viviendas del modelo original; y **este modelo posee dos faldones separados, pero con una misma orientación y pendiente.

Tabla 2 - Especificaciones constructivas y valores de trasmitancia aproximados del Modelo C original

\begin{tabular}{|c|c|c|c|c|c|c|}
\hline Elemento & \multicolumn{2}{|c|}{ Materialidad } & $\begin{array}{l}\text { Conductividad } \\
\mathrm{Kj} /(\mathrm{hmK})\end{array}$ & $\begin{array}{c}\text { Calor } \\
\text { específico }\end{array}$ & $\begin{array}{l}\text { Densidad } \\
\text { aparente }\end{array}$ & $\begin{array}{c}\text { Valor } \\
\text { U }\end{array}$ \\
\hline \multirow{3}{*}{$\begin{array}{c}\text { MUROS } \\
\text { EXTERIORES }\end{array}$} & Estucado de yeso & 3 & 5,0 & 1,01 & 2000,0 & \multirow{3}{*}{2,8} \\
\hline & Ladrillo hueco & 140 & 0,22 & 1,4 & 1400,0 & \\
\hline & $\begin{array}{l}\text { Mortero de } \\
\text { cemento }\end{array}$ & 3 & 5,0 & 1,01 & 2000,0 & \\
\hline \multirow{2}{*}{$\begin{array}{c}\text { PISO Planta } \\
\text { Baja }\end{array}$} & Duela de madera & 20 & 0,47 & 2,5 & 650 & \multirow{2}{*}{1,0} \\
\hline & Losa de concreto & 100 & 5,86 & 0,92 & 1400 & \\
\hline \multirow{3}{*}{ ENTREPISO } & Duela de madera & 20 & 0,47 & 2,5 & 650 & \multirow{3}{*}{0,92} \\
\hline & Losa de concreto & 80 & 5,87 & ,92 & 2400 & \\
\hline & Yeso cartón & 12 & 0,94 & 84 & 700 & \\
\hline \multirow[t]{2}{*}{ CIELO } & $\begin{array}{l}\text { Poliestireno } \\
\text { expandido }\end{array}$ & 80 & 0,155 & & 20 & \multirow[t]{2}{*}{0,53} \\
\hline & Yeso cartón & 12 & 0,94 & ,84 & 700 & \\
\hline TECHUMBRE & Zinc & 0,5 & 208 & 0,390 & 700 & 5,8 \\
\hline $\begin{array}{c}\text { CARPINTERÍ } \\
\text { AS }\end{array}$ & $\begin{array}{l}\text { Aluminio y vidrio } \\
\text { simple }\end{array}$ & & & & & 4,8 \\
\hline
\end{tabular}


Tabla 3 - Especificaciones constructivas y valores de trasmitancia de la vivienda con medidas de eficiencia pasiva de aislamiento en envolvente

\begin{tabular}{|c|c|c|c|c|c|c|}
\hline Elemento & \multicolumn{2}{|c|}{$\begin{array}{l}\text { Materialidad Espesor } \\
\qquad(\mathrm{mm})\end{array}$} & $\begin{array}{l}\text { Conductividad } \\
\mathrm{Kj} /(\mathrm{hmK})\end{array}$ & $\begin{array}{c}\text { Calor } \\
\text { Específico } \\
\mathrm{Kj} /(\mathrm{Kgk}) \\
\end{array}$ & $\begin{array}{c}\text { Densidad } \\
\text { Aparente } \\
\mathrm{Kg} /(\mathrm{m} 3) \\
\end{array}$ & $\begin{array}{l}\text { Valor } \\
\text { U }\end{array}$ \\
\hline \multirow{3}{*}{$\begin{array}{c}\text { MUROS } \\
\text { EXTERIORES }\end{array}$} & $\begin{array}{l}\text { Mortero de } \\
\text { cemento }\end{array}$ & 15 & 5,0 & 1,0 & 2000,0 & \multirow{3}{*}{0,57} \\
\hline & $\begin{array}{c}\text { Poliestireno } \\
\text { expansivo }\end{array}$ & 50 & 0,1 & 1,3 & 25,0 & \\
\hline & $\begin{array}{l}\text { Ladrillo } \\
\text { hueco }\end{array}$ & 140 & 2,6 & 1,0 & 1400,0 & \\
\hline \multirow{4}{*}{ PISO Planta Baja } & $\begin{array}{c}\text { Duela de } \\
\text { madera }\end{array}$ & 25 & 0,5 & 1,2 & 650 & \multirow{4}{*}{0,31} \\
\hline & $\begin{array}{c}\text { Losa de } \\
\text { concreto }\end{array}$ & 80 & 4,1 & 1 & 1400 & \\
\hline & $\begin{array}{c}\text { Fieltro } \\
\text { aislamiento }\end{array}$ & 1,2 & 0,61 & 1 & 1000 & \\
\hline & $\begin{array}{c}\text { Poliestileno } \\
\text { de alta } \\
\text { densidad } \\
\end{array}$ & 100 & 0,13 & 1,25 & 25 & \\
\hline \multirow{3}{*}{ ENTREPISO } & Madera & 25 & 0,5 & 1,2 & 650 & \multirow{3}{*}{1,6} \\
\hline & $\begin{array}{c}\text { Losa de } \\
\text { concreto }\end{array}$ & 80 & 4,1 & 1 & 1400 & \\
\hline & Yeso cartón & 12 & 0,58 & 0,84 & 950 & \\
\hline \multirow{3}{*}{ CIELO } & $\begin{array}{c}\text { Fibra de } \\
\text { vidrio }\end{array}$ & 112 & 0,14 & 0,84 & 12 & \multirow{3}{*}{0,31} \\
\hline & Fieltro & 1,2 & 0,61 & 1 & 1400 & \\
\hline & Yeso Cartón & 12 & 0,58 & 0,84 & 950 & \\
\hline \multirow{2}{*}{ TECHUMBRE } & $\mathrm{PV}$ & 20 & 3,6 & 1 & 2000 & \multirow{2}{*}{ 2,92 } \\
\hline & Terciado & 39 & 0,51 & 1,2 & 650 & \\
\hline CARPINTERÍAS & $\begin{array}{c}\text { PVC y vidrio } \\
\text { doble claro }\end{array}$ & 14 & & & & 3,21 \\
\hline
\end{tabular}

\section{Resultados}

\section{Simulación de demandas térmicas para calefacción}

Se simulan demandas energéticas del modelo de vivienda readaptado volumétricamente y con medidas de eficiencia pasivas; para ello se utilizan parámetros climáticos locales de Meteonorm ${ }^{\circledR}$. El simulador TRNSYS 17.0 y su módulo TRNBUILD se utilizan para estimar las demandas térmicas y las irradiaciones en distintas inclinaciones $\mathrm{y}$ orientaciones. La herramienta considera condiciones climáticas, térmicas, de irradiación solar (directa, difusa y albedo), vientos y características locales al modelo analizado. Con base en ello, las simulaciones muestran el desempeño energético interior, mostrando las demandas por horarios en cada uno de los compartimentos interiores en los que se especifica abastecimiento para calefacción: living-comedor, cocina y dormitorios. Como se puede prever, las simulaciones muestran que hay un incremento en la demanda de calefacción a medida que aumenta el desvío respecto del norte de la fachada captadora (posterior). Con la vivienda perfectamente orientada hacia el norte, la demanda promedio anual por $\mathrm{m}^{2}$ es de $34,45 \mathrm{kWh}$. La máxima demanda para calefacción se observa con la máxima desviación $\left(94^{\circ}\right)$ con un requerimiento de $41,91 \mathrm{kWh} / \mathrm{m}^{2}$; en condiciones intermedias con desvíos de entre $19^{\circ}$ y $55^{\circ}$ - se observa una demanda promedio anual de 35,83 $\mathrm{kWh} / \mathrm{m}^{2}$ y $35,90 \mathrm{kWh} / \mathrm{m}^{2}$, respectivamente. En consecuencia, hay una reducción de irradiación considerable cuando el desvío respecto del norte es muy alto. Cuando la fachada captadora muestra una desviación superior a los $45^{\circ}$ resepcto al óptimo, se incrementa la demanda térmica en un 21,7\%; no obstante, con desvíos intermedios el incremento es relativamente menor $(4,0 \%$ y $4,2 \%)$. Con estrategias pasivas se logra una reducción de demandas térmicas entre un $74 \%$, para un día promedio de junio, y un $70 \%$, para un día promedio de un mes interestacional, respecto de las demandas típicas. 
En cuanto a la demanda eléctrica total por $\mathrm{m}^{2}$, se considera que, con implementación de equipamiento eficiente de bajo consumo, es factible una reducción de consumo del $40 \%$ de acuerdo con estudios previos (CUCHI; DÍEZ; ORGAZ, 2002). Con respecto a demandas de agua caliente sanitaria (ACS), el requerimiento considerado es el necesario para abastecer a cuatro personas. Con estas premisas se espera una reducción del requerimiento total residencial a un $66 \%$ en junio y 59\% en mes interestacional respecto de las demandas típicas.

Situaciones concretas de patrón de ocupación presentan escenarios variables diversos como una posible disminución de necesidad energética en los meses estivales por ausencia de usuarios en período de vacaciones. No obstante, este estudio considera demandas eléctricas obtenidas a partir de encuestas de uso reales y las demandas para calefacción son nulas en época estival. Hay, además, situaciones que, a pesar de habituales, son difíciles de generalizar, como el caso de demanda de ACS en verano, que en muchos casos es mínima (incluso inexistente) por ausencia de usuarios, implicando un potencial desaprovechamiento de la producción térmica, lo que sin duda representa una pérdida de eficiencia por falta de consumo.

\section{Simulación de potencial recolección solar activa y pasiva integradas}

Se somete a análisis la capacidad dimensionalgeométrica de los faldones de techumbre de la vivienda probeta editada para lograr una máxima ocupación de colectores. Se realiza el despliegue de distintas tecnologías considerando una modulación en concordancia con el formato de placas regulares con el criterio de un máximo aprovisionamiento de las demandas propias en primera instancia, buscando luego una máxima generación de excedentes útiles para la red pública.

\section{Integración de colectores BIPV}

El despliegue de colectores BIPV se muestra en la Figura 4 y el rendimiento energético se señala en la Figura 5. La capacidad geométrica de los faldones señala que es posible instalar 54 placas BIPV; esto corresponde a una superficie absorbente solar neta de $70,2 \mathrm{~m}^{2}$. De esta manera, la relación de superficie efectivamente captadora por superficie construida resultante es de 0,71.

En cuanto a la captación pasiva, la simulación muestra que el soleamiento alcanza una importante profundidad en las habitaciones durante junio y que esta se reduce en septiembre. Por el contrario, entre diciembre y enero se impediría la incidencia solar directa, estrategia válida para evitar sobrecalentamiento en época calurosa.

En la primera simulación se compara la producción frente a demandas energéticas incorporando solamente captación y rendimiento de tecnología BIPV. Para ello se realiza una estimación de la producción eléctrica y, conjuntamente, de la posibilidad de recuperación de calor a través del aire utilizado para la refrigeración de células. La estimación muestra las curvas de demandas simuladas y descritas en el apartado previo en la Figura 5.

\section{Figura 4 - Despliegue de colectores BIPV en faldones de modelo propuesto}

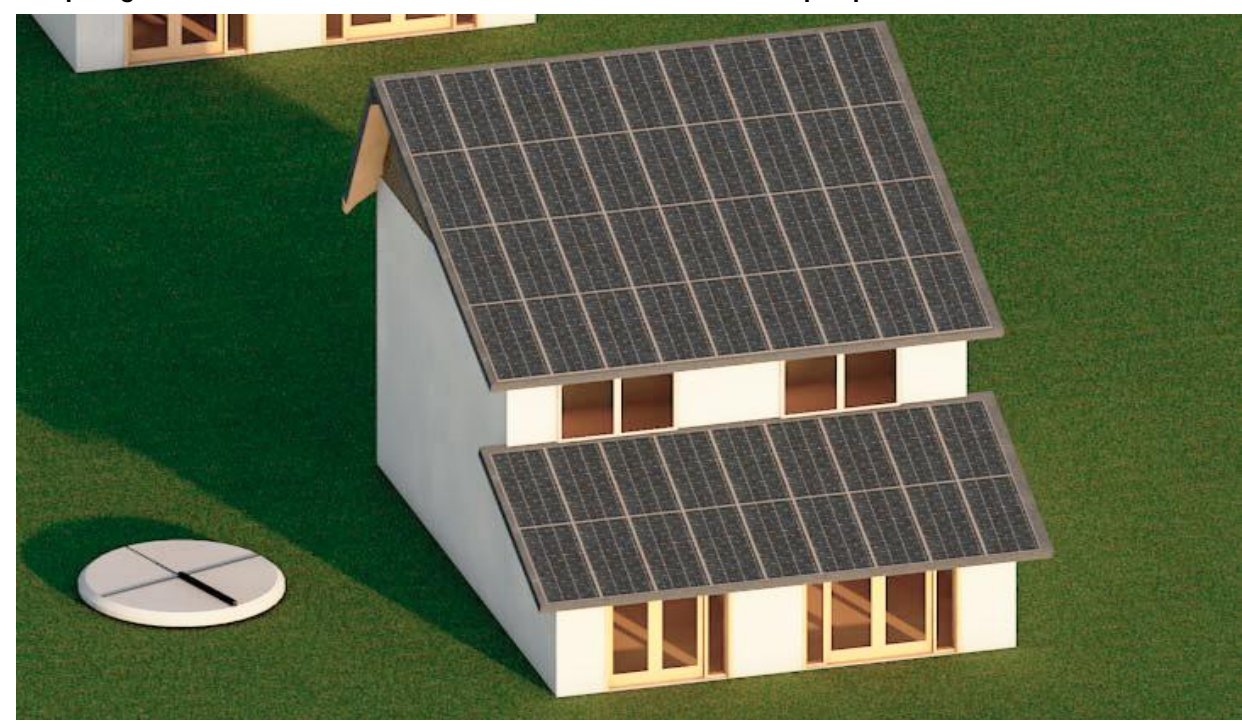

452 Zalamea-León, E. F. ; García-Alvarado, R. H. 
Figura 5 - Demanda energética y provisión eléctrica PV en Modelo C según distintas orientaciones

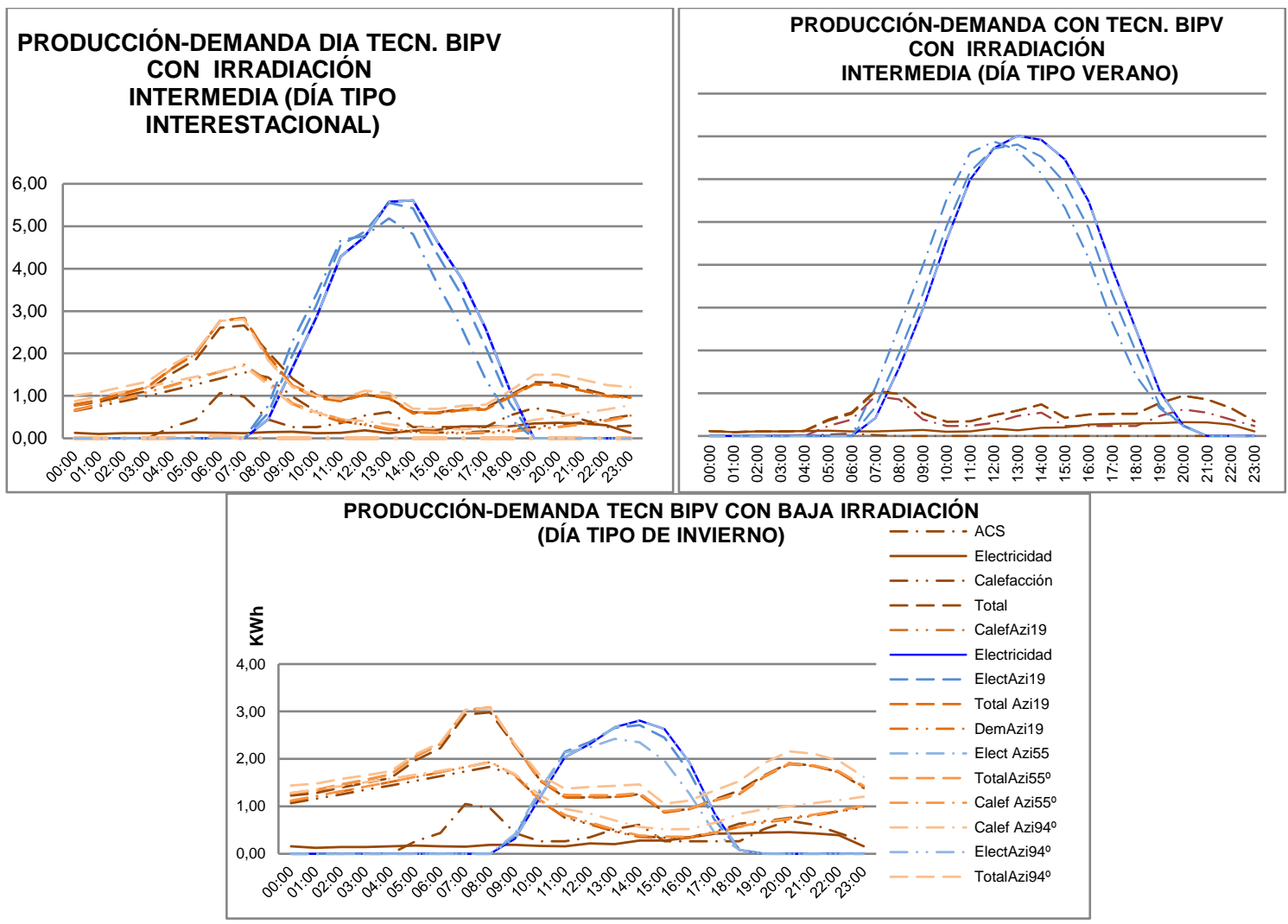

El estudio de desempeño durante días característicos estacionales muestra que con una buena orientación se abastece entre un $43,6 \%$ en día promedio de invierno y 462,5 \% para un día promedio de verano. En consecuencia, se mejora en 3,3 veces la proporción de abastecimiento respecto al modelo con elevada superficie de captación activa, pero sin medidas de captación pasiva analizado en estudio previo (ZALAMEA LEÓN; GARCÍA ALVARADO; SÁNCHEZ ARRIAGADA, 2016). Frente a la demanda anual del Modelo C,estimada en 8.154,5 kWh/año, se produce 14.148,9 $\mathrm{kWh}$ en electricidad logrando un $173,5 \%$ en generación eléctrica respecto a la demanda total anual. El excedente para la red urbana es entonces de 5.994,4 kWh por año. Considerando el alcance promedio de un auto eléctrico -6 $\mathrm{km} / \mathrm{kWh}$ (CONSEJERÍA DE HACIENDA DE MADRID 2012)-, son excedentes que potencialmente permitirían un recorrido vehicular de $36.000 \mathrm{~km}$, distancia teórica que supera con más del doble del recorrido típico de un auto familiar promedio (14.600 km/año; 40 km/día) (SAMWEBER; FISCHHABER; NOBIS, 2015). Sin embargo, es necesario señalar que los excedentes están concentrados en épocas y días de alta irradiación. Adicionalmente, se supone que es una alternativa adecuada el utilizar vehículos eléctricos como opción para el almacenamiento energético y una posibilidad para estabilizar la red en caso de excesos (HAND; KELLY; SAMUEL, 2014; SAMWEBER; FISCHHABER; NOBIS, 2015).

Con una pronunciada desviación en el azimut de fachada y en los faldones captadores $\left(94^{\circ}\right)$, la demanda de la vivienda se incrementa anualmente a 8.893,8 kWh/año, mientras que la generación de $\mathrm{PV}$ se reduce a $12.109,8 \mathrm{kWh}$. A pesar de la inadecuada orientación, aún se trata de vivienda Plus-Zero, aunque implica una reducción de excedentes a $3.216 \mathrm{kWh} / \mathrm{año}$. Los excedentes útiles para alimentación de un vehículo eléctrico alcanzan en este caso para recorrer algo más de $19.000 \mathrm{~km}$, es decir, este valor aún está sobre el promedio de requerimiento de recorrido familiar.

En cuanto al balance de producción y demanda frente a distintas orientaciones, puede decirse que, si la vivienda posee su fachada captadora hacia el oriente, la incidencia solar a baja altura en las mañanas de meses fríos contribuye a disminuir la demanda térmica. En cuanto a la captación activa durante el mes de máxima irradiación, la producción diaria no se ve afectada, incluso con desviación de $94^{\circ}$, como consecuencia del temprano amanecer que provoca varias horas de irradiación y una buena captación con el sol a menor altura de la mañana. Contrariamente, la 
desviación de la orientación de la fachada captadora al poniente no es tan adecuada porque no contribuye con la captación pasiva en horas frías tempranas cuando existe una máxima demanda, sino que, más bien, puede resultar contraproducente por provocar sobrecalentamiento en verano. Por el desvío en orientación la producción anual se reduce hasta en un $4 \%$ como consecuencia de la escasa pendiente de faldones captadores que supone menor pérdida de incidencia solar.

\section{Análisis de producción posible con integración de tecnologías BIPV y BIPVTa conjuntamente}

Se analiza la posibilidad de implementar la recuperación de calor en aire con tecnología híbrida BIPVTa para abastecimiento térmico y eléctrico. Se prevé instalar los colectores híbridos solamente en el faldón superior, ya que con la utilización de la energía térmica captada solamente en esta sección se cubre ampliamente la demanda; por otra parte, la ventilación de celdas PV debería implementarse en ambos faldones (BUKER; RIFFAT, 2015). En la Figura 6 se muestran las curvas de abastecimiento frente a la demanda de días promedio de meses con mínima irradiación y de mes interestacional. No se grafica la recolección térmica durante día promedio de mes con alta irradiación porque normalmente no existen demandas ambientales de calor en esta temporada, aunque existe la posibilidad de contribución en alguna medida para ACS.

Durante el día promedio del mes con mínima presencia de irradiación, la producción eléctrica BIPV supera la demanda eléctrica en tres veces; la producción solamente térmica prácticamente coincide con la demanda térmica. Finalmente, la producción térmica-eléctrica conjunta es un $131 \%$ respecto a la demanda total. En consecuencia, es posible afirmar que con este tipo de instalación se logra una vivienda Plus-Zero incluso en día promedio de temporada con baja irradiación. Sin embargo, es necesario precisar que en días nubosos y fríos extremos no se cubre la totalidad de la demanda, siendo necesario entonces un aprovisionamiento desde la red pública. Adicionalmente se requiere adecuar la vivienda para almacenar y distribuir los excedentes de calor para su utilización nocturna y en horas de demanda (factible con masa térmica por ejemplo) y prever control de evacuación de excedentes para evitar un potencial sobrecalentamiento.

\section{Análisis de producción posible con integración conjunta de tecnologías BISTw más BIPV}

Se procede a realizar el estudio de integración de colectores BIPV y BISTw. La eficiencia de placas BISTw es tomada de colectores Wunder CLS 1808 Solimpeks ${ }^{@}$ y resulta en $\eta_{0}=0,763$, con un coeficiente de pérdida térmica $a_{0}=3,514 \mathrm{Wm}^{-2} \mathrm{~K}^{-1}$ y una superficie absorbente de $1,23 \mathrm{~m}^{2}$ por placa. Se dimensiona la cantidad de colectores con las características mencionadas evitando excedentes térmicos, con lo cual el limitante es el abastecimiento máximo en días de verano para ACS. Por la baja pendiente de faldón con dos placas se logra la condición mencionada $\mathrm{y}$, en consecuencia, queda espacio para 52 placas BIPV. El resultado de la instalación descrita se observa en la Figura 7, donde se aprecia que en la hilada superior las placas térmicas, al poseer un aspecto en concordancia cromática y de formato respecto de los colectores PV, suponen que en apariencia general no sean especialmente notorios, aunque son más resaltantes las franjas laterales requeridas para la conexión de tuberías, que pueden ser tratadas y mimetizadas con consideraciones cromáticas en potenciales tapajuntas.

Figura 6 - Demanda-provisión térmica y eléctrica con tecnología híbrida BIPVTa en probeta de Modelo C

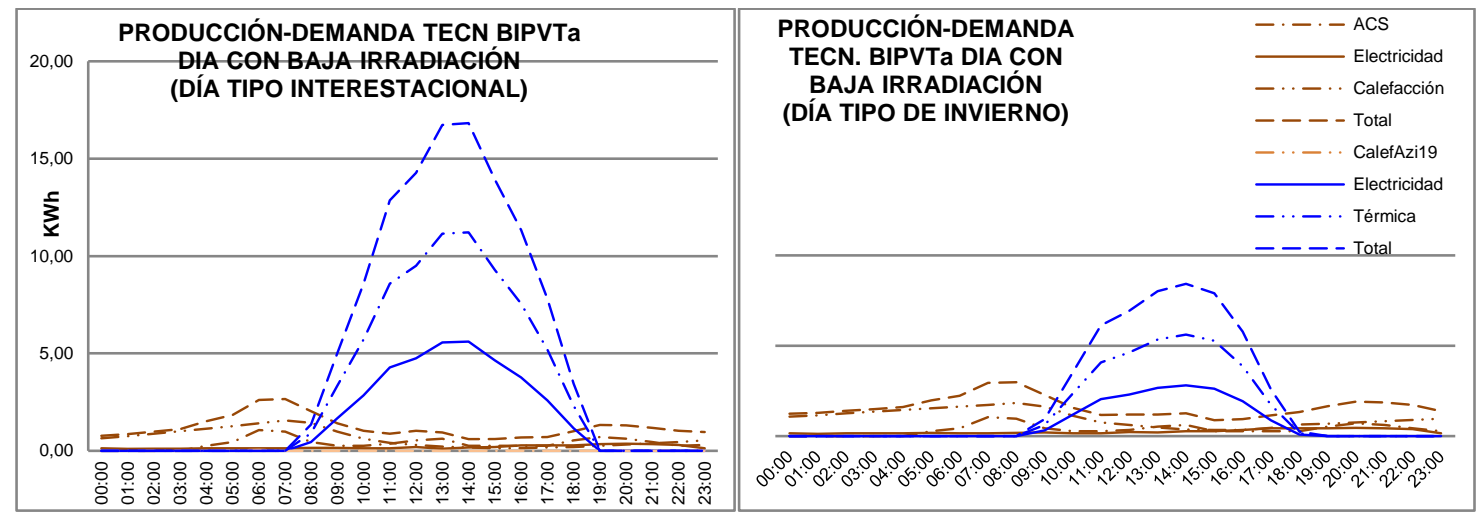

454 Zalamea-León, E. F. ; García-Alvarado, R. H. 
Figura 7 - Instalación de tecnologías BIPV + BISTw en probeta de Modelo C

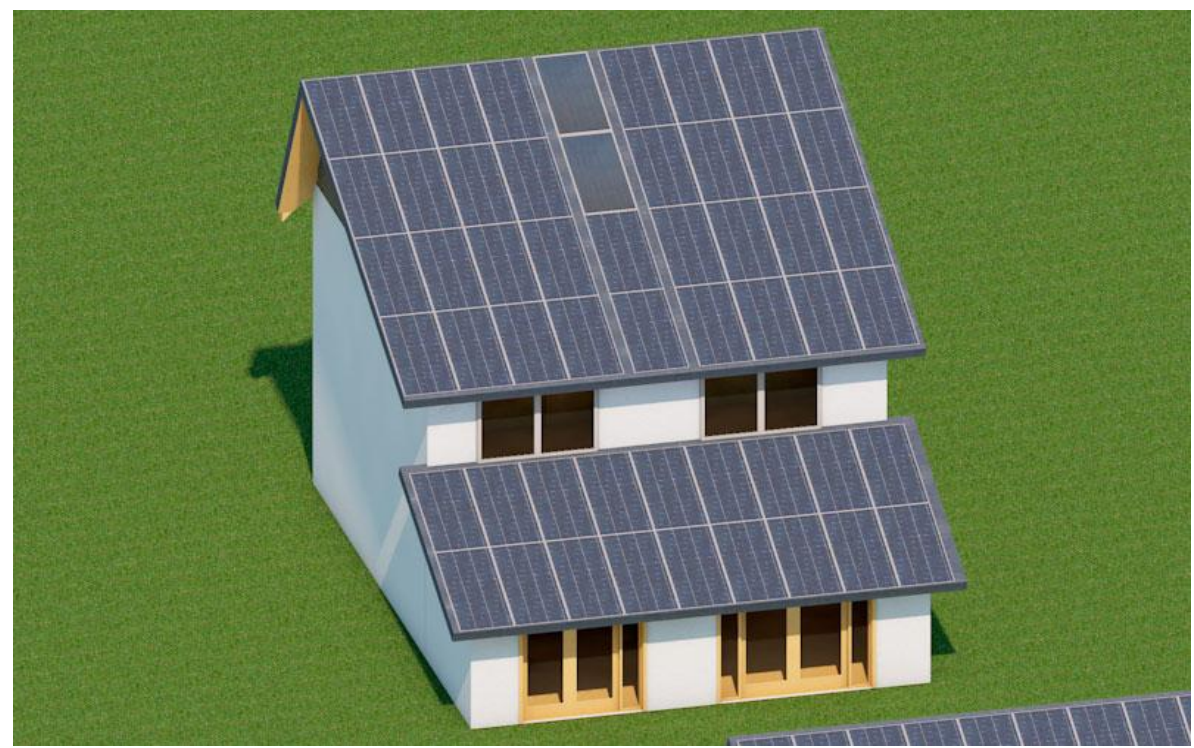

A pesar de tratarse de una vivienda de mayor dimensión respecto al promedio de casos (superficie $26 \%$ mayor), las demandas son menores (59 \% en invierno, $50 \%$ en día interestacional, similares en verano) como consecuencia de las medidas pasivas (aislación y captación directa). Al compararse solamente con el Modelo A, los resultados de captación activa muestran que los márgenes de abastecimiento se duplican en día promedio de diciembre $(498,7 \%$ frente a $250,2 \%$ ), que es casi tres veces superior al día promedio de septiembre (139,8 \% frente a 48,9 $\%$ ) y es 2,8 veces superior en junio (48,1 \% frente a $17.5 \%$ de abastecimiento).

En balance anual, considerando una demanda simulada total de 8.154,5 kWh y una producción térmica y eléctrica de $15.361 \mathrm{kWh}$, se observa una relación producción-demanda de 188,4 \%. Los excedentes eléctricos posibilitarían la circulación de un vehículo eléctrico promedio para un recorrido de 43.000 km durante un año (Figura 8).

\section{Análisis de producción con adopción de tecnologías BIPV, BIPVTw y BIPVTa}

Una última instancia analizada es la conjunción de recolección entre tecnologías BIPVTw para abastecer electricidad y ACS. Además, se integran colectores BIPVTa, para abastecer electricidad conjuntamente con calefacción, y BIPV en superficie de faldón remanente. Se trata de una opción compleja, evidentemente, pero supone estudiar una alternativa en la que, destinando porciones de techumbre en concordancia con los requerimientos energéticos, es factible suplir las demandas totales maximizando la exportación posible (Figura 9).
Como consecuencia de la forma y de la dimensión de los faldones y considerando la necesaria conexión en serie -tanto eléctrica como de red hidráulica en los colectores BIPVTw-, se instalan cuatro placas (las hileras existentes en el modelo son de 4 y 9 placas). No obstante, por condiciones de eficiencia y evasión de sobreproducción, es posible instalar hasta cinco placas híbridas BIPVTw, aunque con cuatro se abastece una proporción superior al 50 \% de la demanda anual de ACS y este valor entra en el rango considerado en la legislación actual para acceder a un subsidio por desplegar colectores en integración arquitectónica (CDT, 2007). Al ocupar la superficie restante del faldón superior con captación BIPVTa, la producción térmica logra cubrir la demanda para calefacción promedio en un día representativo de baja irradiación. En el faldón inferior se considera solamente una producción eléctrica BIPV porque con recolección térmica en este faldón se obtendría únicamente excedentes innecesarios en la mayor parte del tiempo. No obstante, como se ha señalado anteriormente, es adecuada la refrigeración de las celdas siempre, aunque la temperatura no sea útil (JELLE, 2016). Los resultados del balance energético se muestran en la Figura 10.

Bajo este supuesto se logra teóricamente abastecer el $119 \%$ de la demanda promedio en junio, y los excedentes eléctricos llegan a superar hasta en cinco veces la demanda total durante el mencionado mes. La producción es doce veces la demanda eléctrica de día promedio de diciembre. La producción anual se puede estimar con menos exactitud, como sucede siempre que se prevé recolección con aire (parte tendrá que evacuarse, 
sobre todo en verano y parcialmente en días interestacionales). Por ejemplo, bajo la suposición de que la producción térmica captada entre el $1 .^{\circ}$ de junio y el 21 de septiembre con recolección BIPVTa sea de utilidad por completo, la energía útil disponible anual estará en torno de 20.447,1 kWh. Esto alcanza para abastecer la demanda en un $250,7 \%$. Si se destinara el excedente eléctrico PV para mover un auto, alcanzaría para recorrer 73.000 km/año.

Figura 8 - Comparación producción-demanda instalación BIPV+BISTw

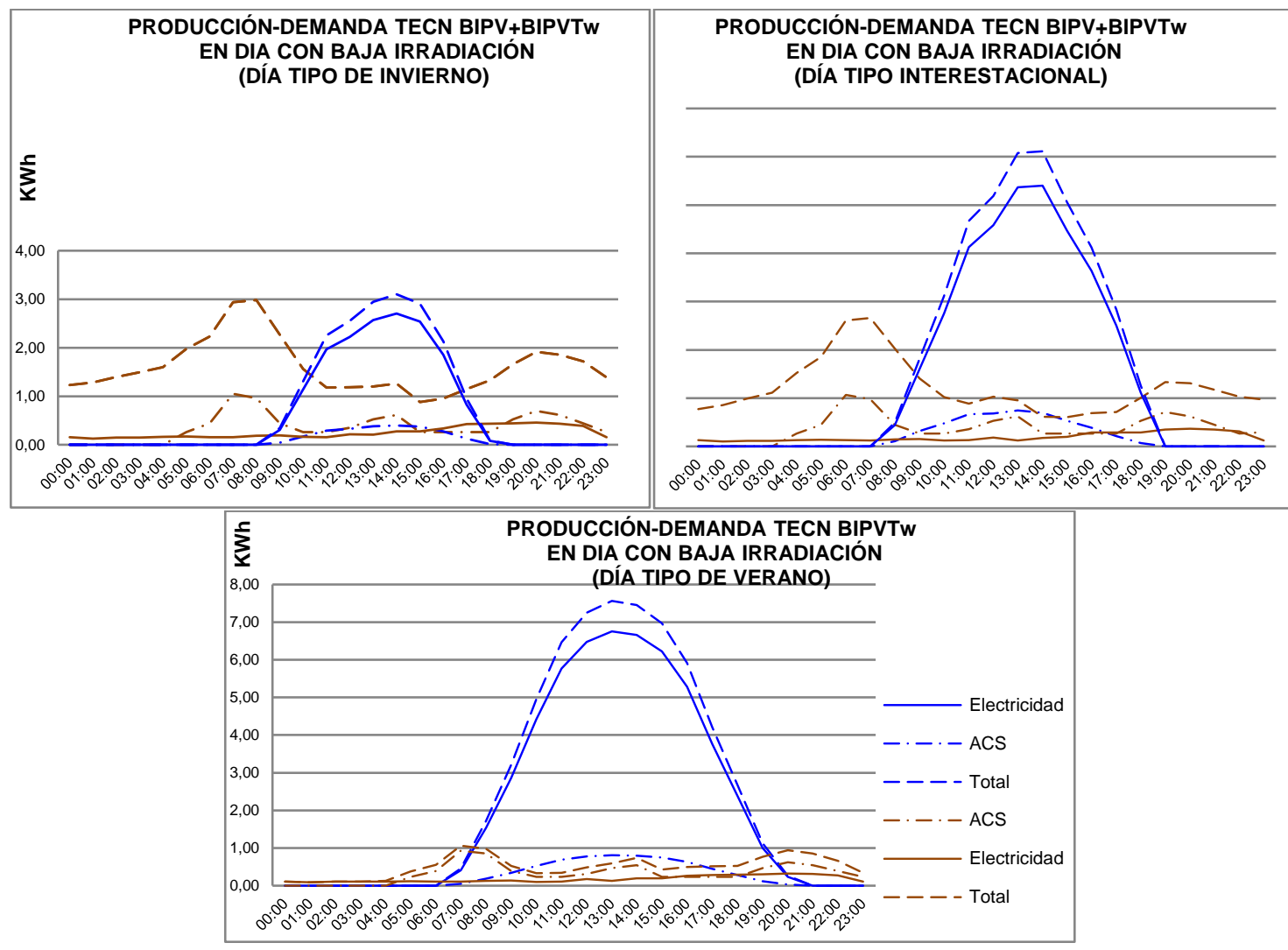

Figura 9 - Instalación de tecnologías híbridas conjuntas BIPVTa más BIPVTw, complementado con BIPV en Modelo C

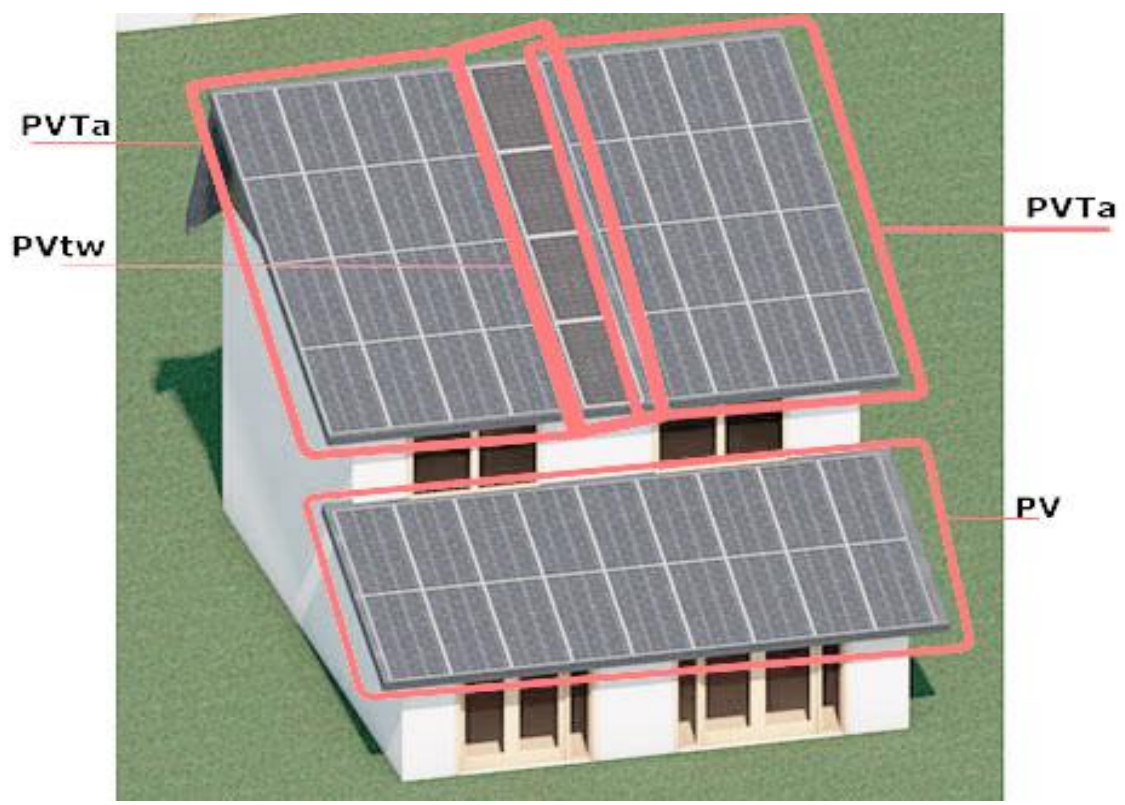


Figura 10 - Comparación de producción y demanda de instalación conjunta de tecnologías BIPVTa + BIPVTw más BIPV

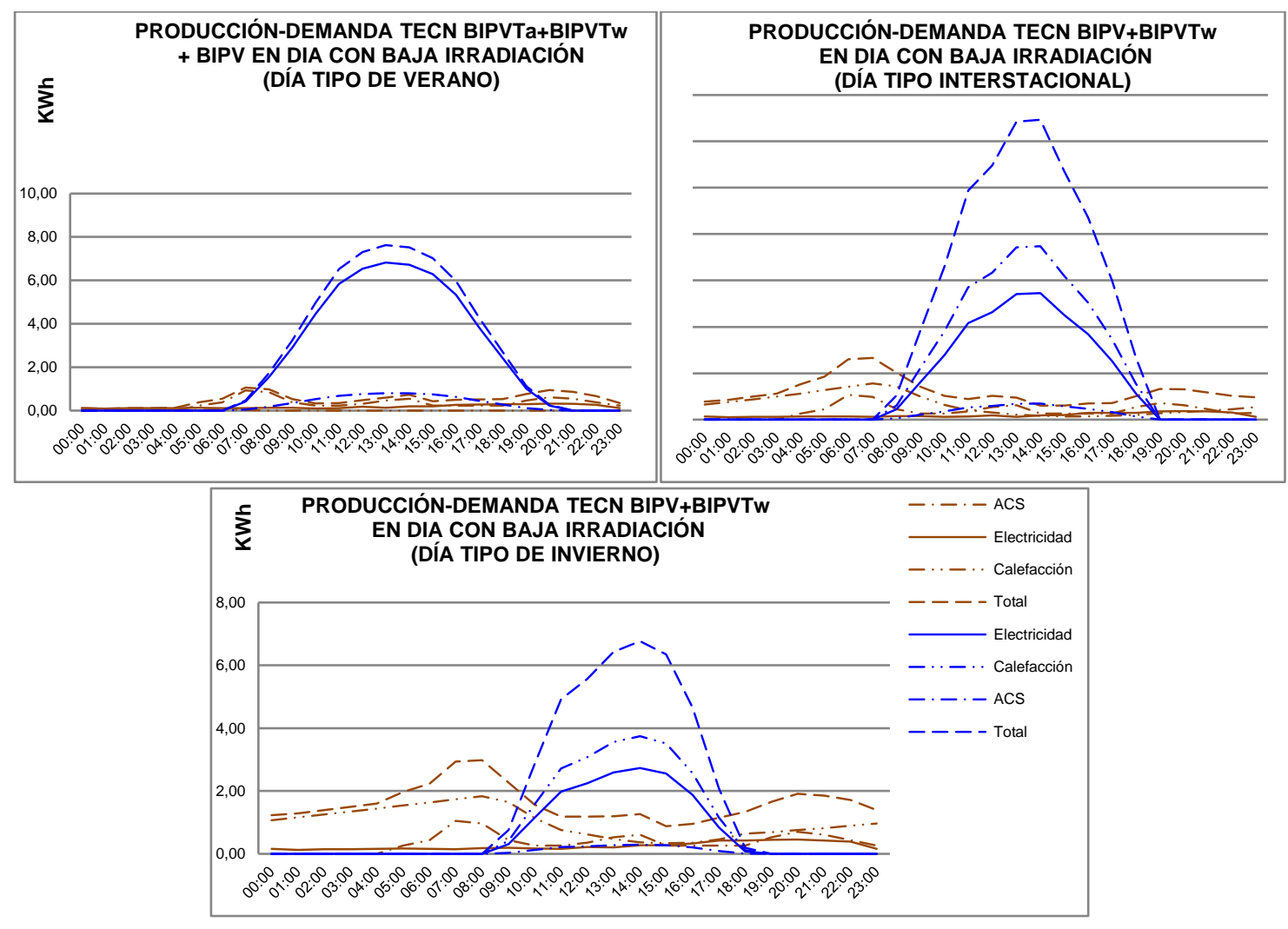

\section{Comparación de los casos analizados en rendimientos respecto de la proporción de demanda satisfecha}

Para una representación concluyente se presenta un gráfico-resumen que muestra la proporción de demanda cubierta con distintas opciones de captación solar. La comparación señala una superioridad notoria de las combinaciones en las que se incluyen colectores híbridos con fluido aire, incrementando el abastecimiento alcanzado en gran medida durante los meses fríos. Sin embargo, es preciso señalar que para lograrlo es necesario alcanzar el aprovechamiento térmico teórico señalado por los referentes. Ello implica una validación a través del desarrollo concreto de la tecnología, calibrando velocidades adecuadas de aire refrigerante para la irradiación existente en la ciudad de Concepción. Así mismo, implica analizar la aplicabilidad de intercambiador de calor, almacenamiento en masa térmica, etc. No obstante, se muestra una gran potencialidad teórica en relación con otras localidades por la superior irradiación y menor desbalance estacional. La proporción de abastecimiento se empareja en buena medida en meses de alta irradiación entre las distintas tecnologías, con superávit de entre $400 \%$ y 500 \%. Por último, se detecta que la opción con menos rendimiento es siempre la utilización de fotovoltaicos exclusivamente (Figura 11).

\section{Estudio de soleamiento}

Complementariamente, se ejecuta un estudio de recorrido solar en la vivienda probeta considerando su localización en la ciudad de Concepción (Figura 12). El resultado señala que en invierno y en primavera no existe autobloqueo de la producción energética por sombra. En días de verano se observa bloqueo desde el faldón superior al inferior durante las primeras horas de la mañana y las últimas de la tarde, lo cual influiría solamente en una hilada de nueve colectores (que deberían conectarse en una serie individual para no afectar todo el rendimiento), aunque esta reducción se da en menos de dos horas de la mañana y de la tarde, únicamente durante los días más largos del año. Finalmente, una separación de $12 \mathrm{~m}$ entre fachadas (delantera y posterior de dos unidades) de dos casas de este mismo modelo con evita el intersombreado entre ellas en el mes crítico de junio, y con una separación de $10 \mathrm{~m}$ el sombreado es mínimo solamente durante días extremos de junio. De este modo es posible configurar conjuntos inmobiliarios similares a los existentes. 
Figura 11 - Comparación de la proporción de demanda satisfecha con distintas combinaciones de tecnologías integradas en el Modelo C, representada en días característicos estacionales

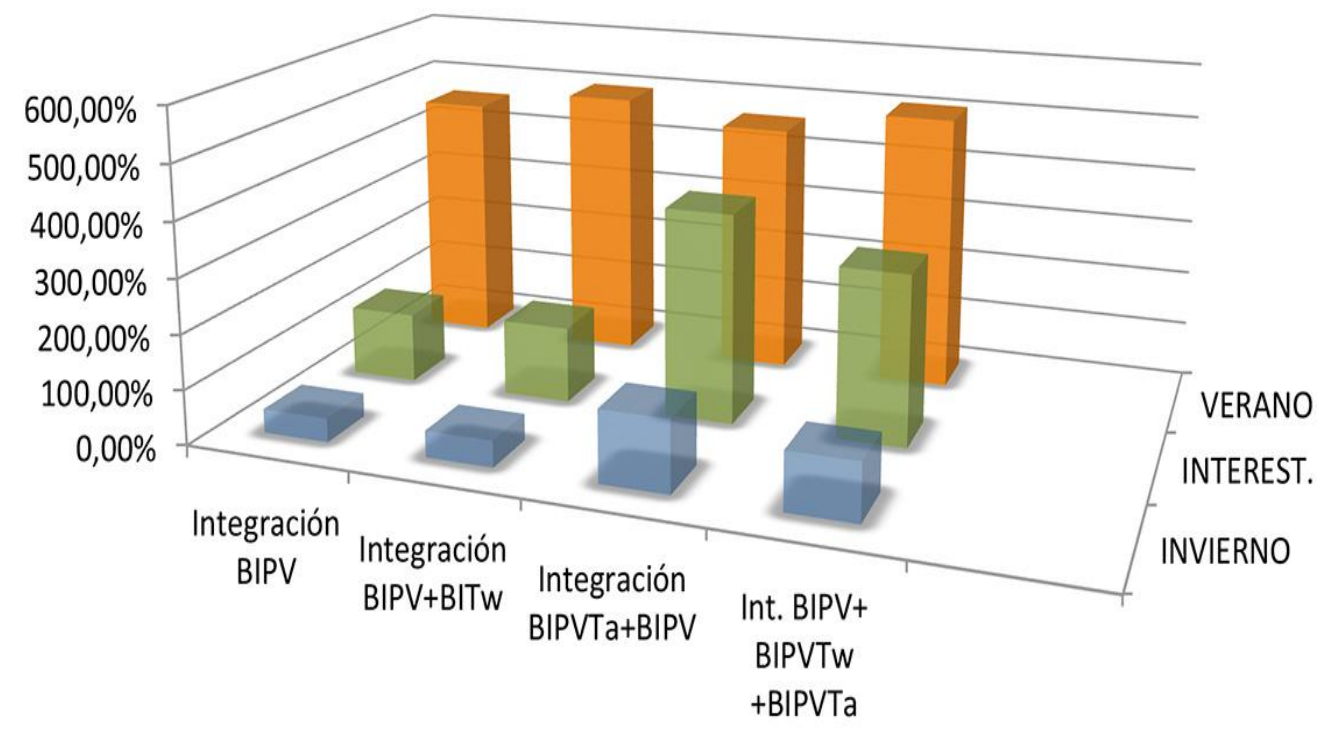

Figura 12 - Estudio del soleamiento durante la mañana, el mediodía y por la tarde

21 de diciembre

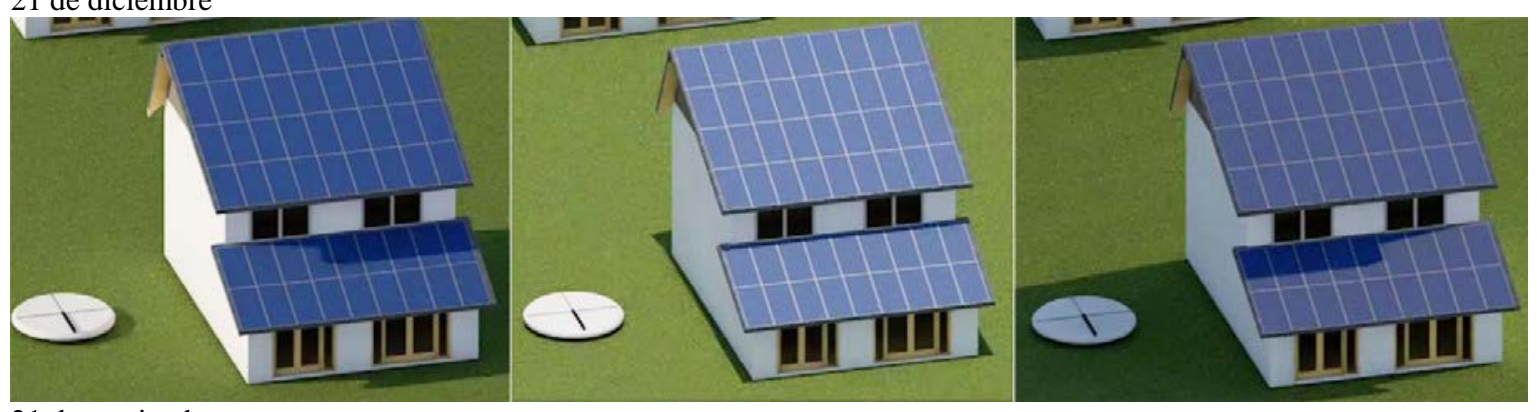

21 de septiembre
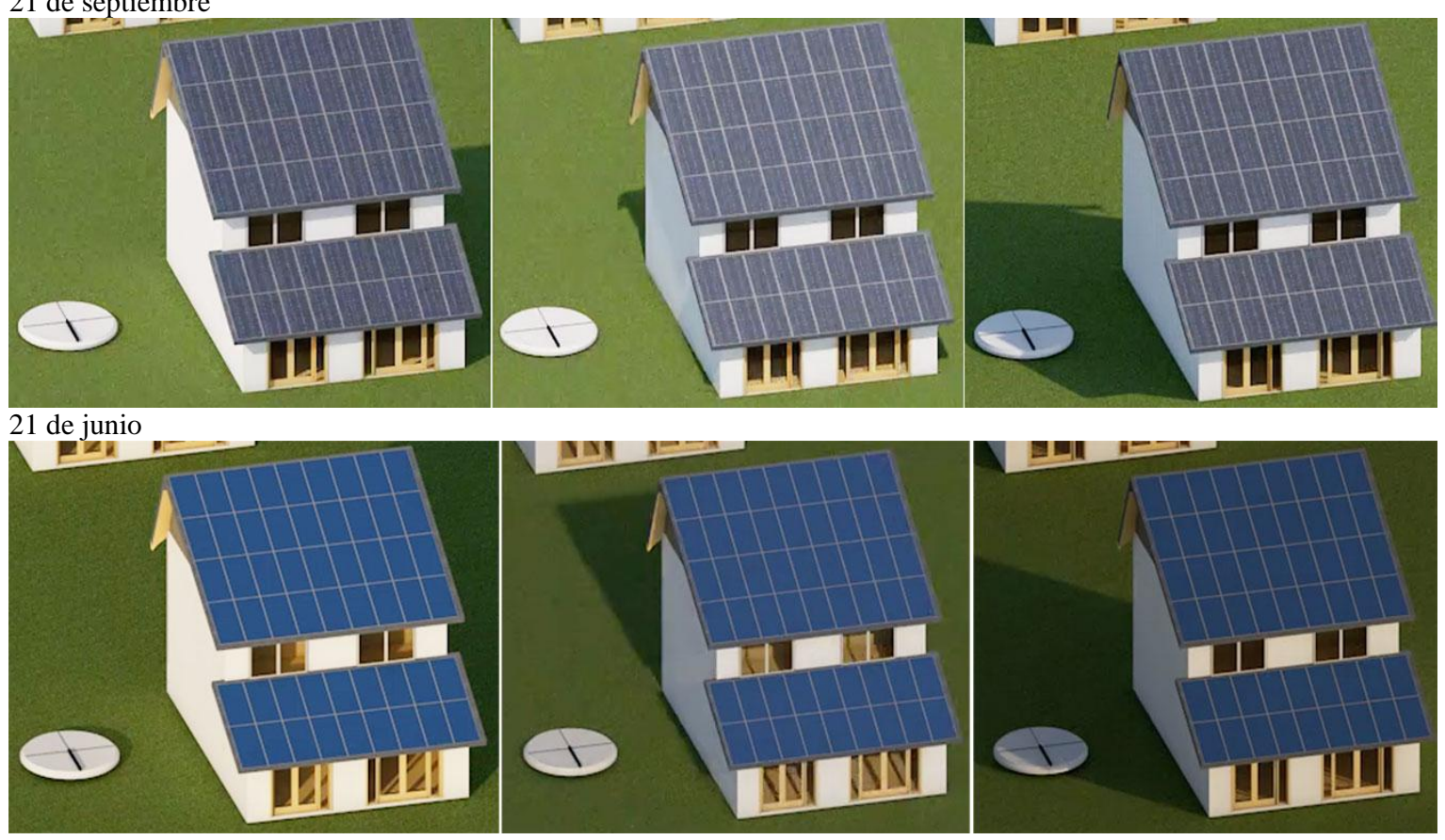

458 Zalamea-León, E. F. ; García-Alvarado, R. H. 


\section{Conclusiones}

Al editar levemente un modelo inmobiliario real seleccionado de emprendimientos vigentes, se ha probado la capacidad de integrar la captación pasiva conjuntamente con medidas de eficiencia energética y con captación activa a través de paneles solares. Se ha medido que se alcanza un potencial energético sustancial, demostrándose que el rendimiento es muy superior a los casos de estudios previos en los que no se consideran medidas pasivas y en cierto compromiso de mantener paradigmas de diseño y programáticos habituales. Se logra una vivienda que, en balance anual, sirve sus propias demandas, alimenta energéticamente en gran medida a la ciudad y destina energía para otros usos, como el transporte. $\mathrm{Al}$ incluir medidas pasivas se observa una reducción a la tercera parte de las demandas típicas de viviendas unifamiliares de iguales características. Por otra parte, al analizar las consecuencias de orientación y la consiguiente reducción en el aprovechamiento pasivo, se aprecia que la reducción de la demanda no supera el $18 \%$. Aplicada la captación activa agresivamente, se estima producir $174 \%$ del gasto residencial, solamente con el despliegue de tecnología BIPV; y hasta dos veces y media las demandas totales si se combinan tecnologías BIPV + BIPVTa + BIPVT $w$ en generación conjunta. Se proponen y dimensionan entonces alternativas de viviendas del tipo Plus-Energy con excedentes importantes que bastan para energizar vehículos eléctricos para realizar recorridos superiores a la distancia promedio transitada por un vehículo familiar de ciudad.

No obstante, es observable un marcado desbalance anual. En verano los excedentes eléctricos superan en hasta doce veces la demanda doméstica, situación en la cual una casa de estas características cumple la función de proveedor energético relevante para la ciudad. Sin embargo, esta situación puede congestionar la red, implicando un necesario funcionamiento en contexto de Smart Grid y medidas de aprovechamiento alternativo, por ejemplo, como estrategia para paliar los déficits de las hidroeléctricas cuando existe máxima producción en verano, situación usual en el ámbito de estudio. Arquitectónicamente, además, resulta en una vivienda con un ingreso solar importante que permite colaborar térmicamente, reduciendo la calefacción y logrando una importante incidencia de luz natural. En cuanto al aspecto arquitectónico resultante, los colectores denotan una nueva textura en techo que, al ser repetitiva, puede derivar en un lenguaje de conjunto, similar al resultado de períodos pasados cuando se introdujo el fibrocemento, la teja asfáltica o la lámina metálica.

\section{Referencias} AGENCIA ESTATAL DE METEOROLOGÍA.
AEMET. Datos Clomatológicos de España.

Disponível em:

$<$ http://www.aemet.es/es/serviciosclimaticos/datos climatologicos>. Acesso em: $29 \mathrm{dez} .2015$.

ATHIENITIS, A. K. et al. A Prototype

Photovoltaic/Thermal System Integrated With

Transpired Collector. Solar Energy, v. 117, n. 1, p. 403-410, 2011.

BUKER, M. S.; RIFFAT, S. B. Building Integrated Solar Thermal Collectors: a review. Renewable and Sustainable Energy Reviews, v. 51, p. 327-346, 2015.

CAMPOS, P. Evaluación Técnico-Económico de Alternativas de Generación Energética in situ en Viviendas en Concepción. Universidad de Concepción, 2015.

CARLISLE, N.; GEET, O. VAN; PLESS, S. Definition of a “Zero Net Energy” Community. Golden: National Renewable Energy Laboratory, 2009.

\section{CORPORACIÓN DE DESARROLLO \\ TECNOLÓGICO. Sistemas Solares Térmicos. Santiago: CDT, 2007.}

CELIS, F. et al. Análisis Energético de las Viviendas del Centro-Sur de Chile.

Arquiteturarevista, v. 8, p. 62-75, 2012.

CHARRON, R.; ATHIENITIS, A. Design and Optimization of Net Zero Energy Solar Homes (AE). ASHRAE Transaction, v. 112, p. 285-296, 2006.

CHEN, F.; YIN, H. Fabrication and LaboratoryBased Performance Testing of a BuildingIntegrated Photovoltaic-Thermal Roofing Panel. Applied Energy, v. 177, p. 271-284, 2016.

CONSERJERIA DE HACIENDA DE MADRID. Guía del Vehículo Eléctrico. 2012. Disponível em: $<$ http://www.cleanvehicle.eu/fileadmin/downloads /Spain/Guida del vehicolo Electrico.pdf $>$. Acesso em: 16 jun. 2017.

\section{CUCHI, A.; DÍEZ, G.; ORGAZ, C. La Cubierta} Captadora en los Edificios de Viviendas.

Barcelona: Institut Tecnologia Construccio, 2002. 
DISCH, R. PlusEnergy: the manifesto. Disponível em:

$<$ http://www.rolfdisch.de/files/pdf/12_PLUSENE RGIE_EIN_MANIFEST_6_englisch.pdf $>$. Acesso em: 2 abr. 2016.

FELDMAN, D. et al. Photovoltaic System Pricing Trends. SunShot, 2014.

FISSORE, A. La Realidad Energética en el Sector Residencial de la Región del Bío-Bío. Santiago: Alianza de Energía y Clima de las Américas, 2009.

GARCÍA, R. et al. Mapa Energético-Solar de Concepción : Cartografía urbana del consumo energético y captación solar en edificaciones residenciales de Concepción, Chile 1 . Norte Grande, v. 59, p. 123-144, 2014.

GARCÍA ÁlVARADO, R.; GONZÁLEZ, A. Condiciones de Forma y Desempeño Energético de Viviendas Unifamiliares en el Centro: sur de Chile 1 Form conditions and energy performance of single - family housing in Central - South Chile 1. Revista INVI, v. 29, n. 80, p. 111-141, 2014.

HABERL, J. S.; CHO, S. Energy Systems. Working Group III - Mitigation of Climate Change, aug. 2014.

HACHEM, C. Investigation of Design Parameters for Increased Solar Potential of Dwellings and Neighborhoods. PhD - Thesis, Concordia University, Montreal, 2012.

HAND, J.; KELLY, N.; SAMUEL, A. Modelling the Impact of Integrated Electric Vehicle Charging and Domestic Heating Strategies on Future Energy Demands Domestic Heating Strategies on Future Energy Demands. In: INTERNATIONAL CONFERENCE ON SYSTEM SIMULATION IN BUILDINGS, 9., Liege, 2014. Proceedings... Liege, 2014.

HASTINGS, S. R.; WALL, M. Sustainable Solar Housing: volume 2: exemplary buildings and technologies. Earthscan: London \& Sterling VA, 2007.

HATT, T. et al. Alto Confort Interior con Mínimo Consumo Energético a Partir de la Implementación del Estándar “ Passivhaus ” en Chile. Revista de la Construcción, v. 11, n. 2, p. 123-134, ago. 2012.

INSTITUTO NACIONAL DE ESTADÍSTICAS. Demográficos y Vitales. Disponível em: $<$ http://www.ine.cl/canales/chile_estadistico/famili as/demograficas_vitales.php $>$. Acesso em: 16 jun. 2017.
JELLE, B. P. Building Integrated Photovoltaics : a concise description of the current State of the Art and possible research pathways. Energies, v. 9, n. 21, p. 1-30, 2016.

KALOGIROU, S. Building Integrated Solar Thermal System. In: EURO-ELECS CONFERENCE: CONNECTING PEOPLE \& IDEAS, Guimarães, 2015. Anais... Guimaraes: Universidade do Minho, 2015.

KAZANCI, O. B. et al. Sustainable Heating, Cooling and Ventilation of a Plus-Energy House Via Photovoltaic/Thermal Panels. Energy and Buildings, v. 83, p. 122-129, 2014.

LUND, P. Large-Scale Urban Renewable Electricity Schemes: integration and interfacing aspects. Energy Conversion and Management, v. 63, p. 162-172, 2012.

MINENERGIA. Norma Técnica que Determina Algoritmo Para la VERIFICACIÓN de la Contribución Solar mínima de los Sistemas Solares Térmicos Acogidos a la Franquicia TRIBUTARIA de la Ley No 20.365. 2009.

Disponível em:

$<$ http://antiguo.minenergia.cl/minwww/export/site s/default/02_Noticias/descargas_noticias/Norma_T ecnica_Actualizada.pdf $>$. Acesso em: 16 jun. 2017.

MINENERGIA. Modificaciones a la ley General de Servicios Eléctricos Respecto de la Generación de Energía Eléctrica con Fuentes de Energías Renovables no Convencionales. Chile: Biblioteca del Congreso nacional de Chile, 2013.

NOGUCHI, M. Net Zero-Energy Home Design Strategies Learned from Canadian Experience. Open House International, v. 33, n. 3, p. 88-95, 2008.

PELLAND, S.; POISSANT, Y. An Evaluation of the Potential of Building Integrated Photovoltaics in Canada. Renewable Energy, p. 8, 2006.

PROGRAMA DE LAS NACIONESUNIDAS PARA EL DESARROLLO; MINENERGIA.

Algoritmo_fchart v3. Disponível em: <http://www.programasolar.cl>. Acesso em: 16 jun. 2017.

SALPAKARI, J.; MIKKOLA, J.; LUND, P. D. Improved Flexibility With Large-Scale Variable Renewable Power in Cities Through Optimal Demand Side Management and Power-to-Heat Conversion. Energy Conversion and Management, v. 126, p. 649-661, 2016. 
SAMWEBER, F.; FISCHHABER, S.; NOBIS, P. Electric Mobility as a Functional Energy Storage in Comparison to On-Site Storage Systems for Grid Integration. Energy Procedia, v. 73, p. 94102, 2015.

\section{SOLARWALL. PV/Thermal; Hybrid Solar}

Heating + Electricity. Disponível em:

$<$ http://solarwall.com/en/products/pvthermal.php>. Acesso em: 3 mar. 2015.

TRIPANAGNOSTOPOULOS, Y. et al. Hybrid Photovoltaic/Thermal Solar Systems. Solar Energy, v. 72, n. 3, p. 217-234, 2002.

WEGERTSEDER, P. et al. Barreras y Oportunidades Observadas en la Incorporación de Estándares de Alta Eficiencia Energética en la Vivienda Social Chilena Barriers and Opportunities Observed in the Incorporation of High Energy Efficiency Standards in Chilean Social Housing. Arquitectura y Urbanismo, v. 35, n. 3, p. 37-49, 2014.

ZALAMEA, E. F.; GARCÍA, R.; SÁNCHEZ, R. Influencia de la Geometría de Techumbre de Vivienda Unifamiliar para Integración de Enegía Solar Activa (BIPVTa). Architecture, City and Environment, v. 10, n. 30, p. 57-74, 2016.
ZALAMEA, E.; GARCÍA ALVARADO, R. Roof Characteristics for Integrated Solar Collection in Dwellings of Real- Estate Developments in Concepción, Chile. Revista de la Construcción Journal of Construction, v. 36, n. 133, p. 36-44, 2014.

ZALAMEA LEÓN, E.; GARCÍA ALVARADO, R.; SÁNCHEZ ARRIAGADA, R. Assessment of Integrated Performance and Roof Geometry for Solar Energy. Open House International, v. 41, n. 4, 2016.

ZONDAG, H. A. Flat-plate PV-Thermal Collectors and Systems: A review. Renewable and Sustainable Energy Reviews, v. 12, p. 891959, 2008.

\section{Agradecimientos}

Este trabajo es derivado del proyecto de investigación Conicyt AKA ERNC 007 CON*FIN, de la Universidad del Bio Bio, Chile, así como del proyecto URBENERE-CYTED 715RT0497, y Determinación de potencial de integración arquitectónica de captación solar activa en tipología constructiva de baja altura en centro patrimonial de ciudades andinas. Caso de Estudio Cuenca, Ecuador, del Centro de Investigaciones de la Facultad de Arquitectura de la Universidad de Cuenca.

\section{Esteban Felipe Zalamea-León}

Facultad de Arquitectura y Urbanismo | Universidad de Cuenca | Av. 12 de Abril, s/n y Agustín Cueva | Cuenca - Ecuador | Tel.: +5939 8331-1604 | E-mail: esteban.zalamea@ucuenca.edu.ec

\section{Rodrigo Hernán García-Alvarado}

Departamento de Diseño y Teoría de la Arquitectura | Universidad del Bio Bio | Av. Collao, 1202 | Concepción - Chile | CP 4030000 | Tel.: + 56 (41) 311-1328| E-mail: rgarcia@ubiobio.cl

Revista Ambiente Construído

Associação Nacional de Tecnologia do Ambiente Construído

Av. Osvaldo Aranha, 99 - 3o andar, Centro

Porto Alegre - RS - Brasil CEP $90035-190$

Telefone: +55 (51) 3308-4084 Fax: +55 (51) 3308-4054

www. seer. ufrgs. br/ ambienteconstruido

E-mail: ambienteconstruido@ufrgs.br 